\title{
Autonomous Docking System untuk Mobile Robot Berbasis Citra pada Stasiun Pengisian Daya Nirkabel
}

\author{
Ariestya Putra Susanto, Muhammad Rivai, Tasripan \\ Departemen Teknik Elektro, Fakultas Teknologi Elektro, \\ Institut Teknologi Sepuluh Nopember \\ e-mail:muhammad_rivai@ee.its.ac.id
}

\begin{abstract}
Abstrak - Teknologi pada robot mulai dikembangkan untuk dapat bekerja di luar ruangan selama 24 jam penuh. Permasalahan yang muncul adalah robot ini tidak memiliki daya baterai yang cukup agar dapat bekerja selama seharian. Sebagai solusinya, maka dibangun stasiun pengisian daya di beberapa titik untuk mengisi daya pada baterai robot. Teknologi yang digunakan untuk mencari keberadaan stasiun pengisian daya adalah dengan menggunakan GPS. Akan tetapi GPS tidak selalu memberikan titik akurat dari keberadaan stasiun pengisian daya. Pada penilitian ini, metode yang ditawarkan adalah dengan menggunakan kamera untuk mendeteksi dan menuju stasiun pengisian daya dengan asumsi robot telah menggunakan GPS untuk menemukan koordinatnya. Kamera akan mendeteksi objek dalam bentuk dua dimensi, kemudian citra yang ditangkap akan dikonversi ke bentuk channel HSV untuk mengetahui warna dari objek yang dijadikan target. Setelah itu, contour dari objek akan dicari untuk mendapatkan luas dan titik tengah objek. Dua parameter tersebut akan digunakan untuk menjalankan robot dengan motor dc yang akan dikontrol secara proporsional untuk mendapatkan hasil yang lebih presisi. Hasil yang didapat dari uji coba pada mobile robot adalah bahwa titik tengah objek lebih efektif untuk dijadikan set point dengan tingkat keberhasilan yang didapat pada pengujian akhir sebesar $75 \%$.
\end{abstract}

Kata kunci-Autodocking, Citra, Deteksi Objek, Kamera, Mobile Robot.

\section{PENDAHULUAN}

$\mathrm{P}$ ADA area yang luas seperti area industri migas memiliki banyak pipa yang kebocorannya sulit dideteksi karena cakupan wilayah yang luas dan dibutuhkannya sensor untuk mendeteksi adanya kebocoran gas. Untuk itu diperlukan sebuah alat yang mampu bergerak berupa robot untuk melakukan deteksi terhadap kebocoran gas. Dengan berkembangnya teknologi saat ini maka berpengaruh terhadap perkembangan sistem yang ada pada robot [1].

Saat ini teknologi pada robot mulai dikembangkan untuk melakukan pekerjaaan di luar ruangan. Permasalahan yang muncul adalah baterai pada robot sangat terbatas untuk melakukan pekerjaan di luar ruangan sehingga diperlukan cara untuk menjaga agar robot tersebut dapat bekerja selama 24 jam tanpa harus dipengaruhi oleh permasalahan yang timbul oleh terbatasnya daya pada baterai robot.
Alternatif yang dapat digunakan adalah dengan membangun stasiun pengisian daya pada baterai mobile robot. Dengan adanya stasiun pengisian daya pada baterai robot, maka diperlukan suatu sistem pada robot agar dapat melakukan docking pada tempat pengisian daya dengan posisi yang tepat agar daya yang terisi pada robot menjadi optimal [2].

Sistem yang akan dibuat untuk melakukan autodocking terdiri dari sensor yang nantinya diharapkan dapat menemukan lokasi dari stasiun pengisian daya dan membuat robot bergerak menuju stasiun pengisian daya. Saat ini telah dibuat sistem pada mobile robot dengan menggunakan sensor ultrasonik untuk mendeteksi jarak terhadap target [3]. Perangkat yang dapat digunakan dapat berupa kamera yang akan menangkap citra dan dapat menentukan target berupa stasiun pengisian daya. Karena saat mobile robot hanya mengandalkan perangkat pelacak posisi seperti GPS, maka hasilnya belum tentu akurat sehingga dibutuhkan perangkat tambahan untuk memastikan bahwa mobile robot dapat bergerak mencapai target dan melakukan docking pada stasiun pengisian daya.

\section{METODE PENELITIAN}

Pada bagian ini dijelaskan mengenai perancangan sistem secara keseluruhan yang meliputi perancangan perangkat keras, perangkat lunak dan perancangan mekanik dari mobile robot. Perangkat mekanik merupakan badan dari robot yang dirangkai dengan bahan akrilik dan disusun menggunkan dua roda belakang yang digerakkan oleh motor dc dan satu roda depan yang berupa roda bebas. Sedangkan perangkat elektrik yang akan digunakan yaitu Raspberry $\mathrm{Pi}$, webcam, dan rangkaian buck converter. Perangkat lunak terdiri dari program pengolahan citra yang didapat dari kamera untuk melakukan deteksi target berupa stasiun pengisian daya dan memberi perintah untuk mendekati target.

\section{A. Diagram Blok Sistem}

Diagram blok sistem menjelaskan rangkaian kerja secara keseluruhan dari auto docking yang akan dilakukan oleh mobile robot terhadap stasiun pengisian daya. Sistem kerja dari mobile robot yaitu dengan menggunakan kamera untuk melakukan deteksi terhadap target dan menggunakan motor dc agar robot dapat bergerak menuju target. 


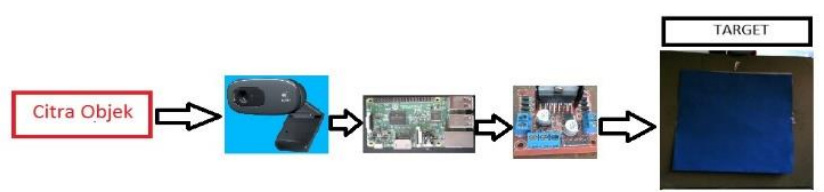

Gambar. 1. Blok diagram sistem Mobile Robot.

Gambar 1 menunjukkan blok diagram sistem secara keseluruhan pada mobile robot untuk melakukan docking otomatis terhdap stasiun pengisian daya nirkabel. Komponen yang akan dijadikan set point pada sistem ini adalah titik tengah dari target yang akan dituju. Kamera akan digunakan sebagai perangkat untuk menangkap citra dan diolah untuk mendapatkan posisi target. Pengendali PID akan memberi kontrol terhadap driver motor untuk mengatur sinyal PWM yang akan digunakan untuk mengatur kecepatan motor dc dalam melakukan pergerakan menuju target.

Perangkat keras pada sistem mobile robot terdiri dari:

1) Raspberry Pi

Raspberry $P i$ digunakan untuk mengolah data berupa citra untuk menentukan pergerakan dari mobile robot.

2) Driver Motor dan Motor

Driver motor digunakan untuk mengatur sinyal PWM menjadi besaran tegangan yang berfungsi sebagai sumber dari motor pada mobile robot.

3) Webcam

Webcam adalah kamera yang digunakan untuk mengambil data masukan berupa citra yang kemudian akan diolah oleh Raspberry Pi.

4) Buck Converter

Buck converter adalah rangkaian elektronika yang digunakan untuk menurunkan tegangan agar menjadi 5 volt untuk digunakan pada Raspberry $P i$.

Perangkat lunak untuk sistem auto docking.

Perangkat lunak yang dirancang adalah untuk melakukan pengolahan citra agar dapat mendeteksi objek yang dijadikan target dan memberi perintah pada mobile robot untuk bergerak menuju target.

Gambar 1 menunjukkan ketika kamera telah menangkap citra dari objek maka citra tersebut akan diproses ke dalam Raspberry Pi untuk menentukan objek target yang harus dituju oleh mobile robot. Apabila objek adalah target maka Raspberry Pi akan memberi perintah kepada motor driver untuk menggerakkan motor dc menuju target berupa stasiun pengisian daya nirkabel. Kecepatan dan arah motor dc diatur oleh pengendali PID [4][5]

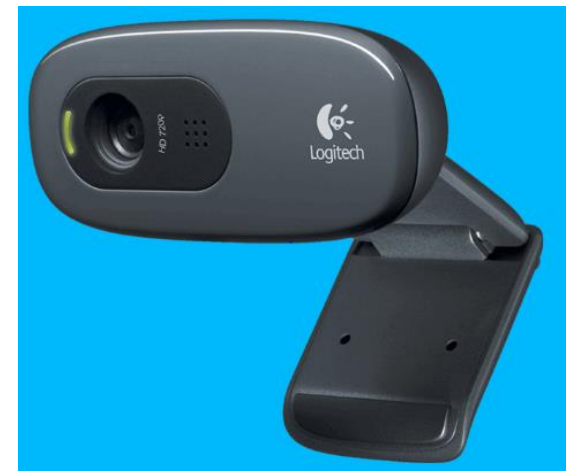

Gambar. 2. Webcam Logitech C270 [6].

\section{B. Perancangan Perangkat Keras}

Perangkat keras pada mobile robot meliputi komponen buck converter, webcam, motor driver, dan Raspberry Pi. Buck converter dengan output USB mini berfungsi mengubah tegangan dari sumber dari sumber berupa baterai 18650 sebesar 7,4 volt menjadi tegangan 5volt yang dijadikan sebagai sumber tegangan pada komponen - komponen dari mobile robot diantaranya kamera berupa webcam dan mini PC Raspberry Pi 3 .

Webcam merupakan sebuah kamera yang nantinya akan digunakan untuk menangkap citra dan hasilnya akan diolah untuk mendapatkan data berupa citra dari objek yang akan dituju oleh mobile robot sehingga dapat dilakukan docking otomatis terhadap objek tersebut. Objek yang dituju adalah stasiun pengisian daya nirkabel.

Kamera tidak hanya melakukan deteksi objek tetapi juga melakukan proses perhitungan jarak terhadap objek tersebut. Kamera yang digunakan adalah webcam Logitech c270 seperti yang terlihat pada Gambar 2 [6].

Raspberry Pi digunakan untuk mengolah data berupa citra yang ditangkap oleh kamera dan dilakukan proses deteksi objek. Setelah titik tengah dari objek didapatkan, maka raspberry memberi perintah kepada motor driver untuk menjalankan motor dc melalui dua buah pinout agar dapat menjalankan motor kanan dan kiri serta menggunakan PWM untuk mengubah kecepatan motor dc.

Driver motor L298 merupakan komponen yang berfungsi sebagai penggerak dan pengatur kecepatan motor dc. Pin input berfungsi menerima data dari raspberry yang nantinya akan diolah untuk dikeluarkan melalui pin output yang akan menggerakkan motor dc. Pin enable berfungsi sebagai pengolah sinyal PWM untuk mengatur kecepatan motor dc. Pin $12 \mathrm{~V}, 5 \mathrm{~V}$, dan pin ground digunakan sebagai sumber tegangan untuk motor driver agar dapat menjalankan motor dc [7]. 


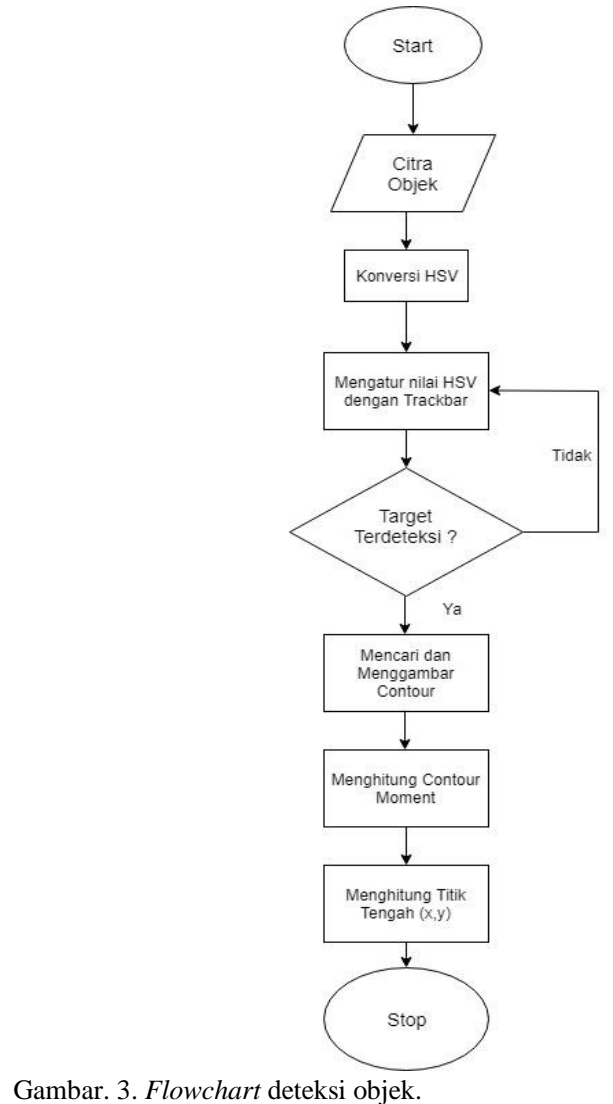

\section{Perancangan Perangkat Lunak Deteksi Objek}

Gambar 3 menunjukkan diagram blok sistem yang menjelaskan rangkaian kerja secara keseluruhan dari auto docking yang akan dilakukan oleh mobile robot terhadap stasiun pengisian daya. Sistem kerja dari mobile robot yaitu dengan menggunakan kamera untuk melakukan deteksi terhadap target dan menggunakan motor dc agar robot dapat bergerak menuju target. Pada bagian ini, perancangan perangkat lunak berupa proses pengolahan citra yang ditujukan untuk mendeteksi objek yang akan dijadikan target berupa stasiun pengisian daya nirkabel dan memberi perintah pada mobile robot untuk bergerak menuju ke target [8], [9]. Proses ini akan dijalankan oleh Raspberry Pi.

Perangkat lunak dimulai saat pengambilan citra. Setelah mendapat citra dari objek, maka nilai contour dari objek akan dicari dan diGambarkan. Setelah contour dari objek telah didapat, maka langkah berikutnya adalah mencari luas permukaan objek yang terlihat menggunakan contour moment. Dari nilai moment dapat dihitung titik tengah objek dengan membagi luas dengan moment 10 untuk sumbu $\mathrm{x}$ dan moment01 untuk sumbu y [10], [11].

\section{Perancangan Perangkat Lunak Kontrol Kecepatan Motor}

Gambar 4 menunjukkan perancangan perangkat lunak untuk mengatur kecepatan motor dengan menggunakan pengendali proporsional. Pengendali proporsional dirancang dengan melakukan setting pada nilai Kp (gain) dan menghitung nilai error yang didapatkan dengan mencari selisih antara nilai set point dengan nilai yang muncul dari output.

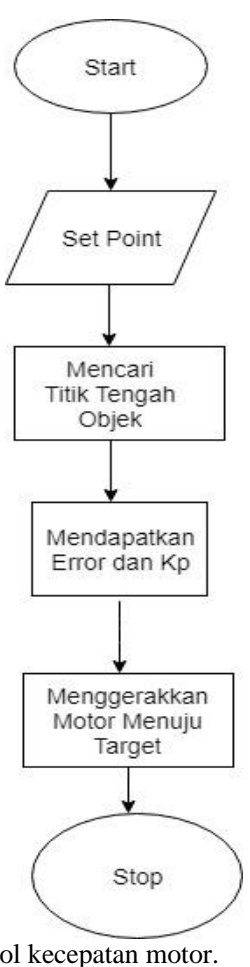

Gambar. 4. Flowchart kontrol kecepatan motor.

Nilai set point yag digunakan adalah nilai dari titik tengah dari frame yaitu 319 pixel di sumbu x dan 239 di sumbu y. Output dalam hal ini berupa titik tengah objek yang telah dideteksi menggunakan kamera. Nilai yang didapat dari pengendali proporsional digunakan untuk mengatur sinyal PWM pada motor driver yang berfungsi mengatur kecepatan dan arah motor dc dalam bergerak mendekati stasiun pengisian daya [12], [13].

\section{HASIL DAN DISKUSI}

\section{A. Realisasi Mobile Robot}

Gambar 5 menunjukkan mobile robot beserta komponen penyusunnya yang digunakan dalam penelitian ini. Sedangkan Gambar 6 merupakan sebuah sistem pengisian daya nirkabel yang terdiri dari pelacak cahaya matahari, stasiun pengisian daya nirkabel, dan mobile robot yang akan melakukan autodocking pada stasiun pengisian daya. Gambar 7 merupakan target yang akan dideteksi oleh kamera dan hasilnya akan diolah untuk memberikan perintah pada mobile robot agar bergerak menuju target yang sudah terpasang pada stasiun pengisian daya untuk melakukan autodocking.

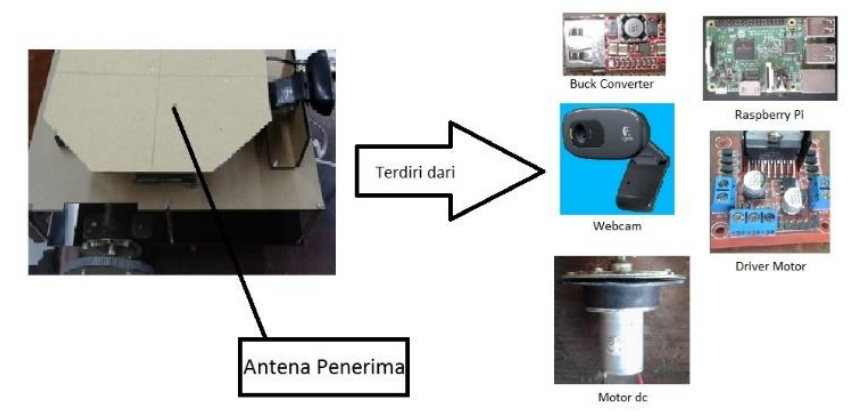

Gambar 5. Hasil realisasi Mobile robot dan komponen penyusunnya. 


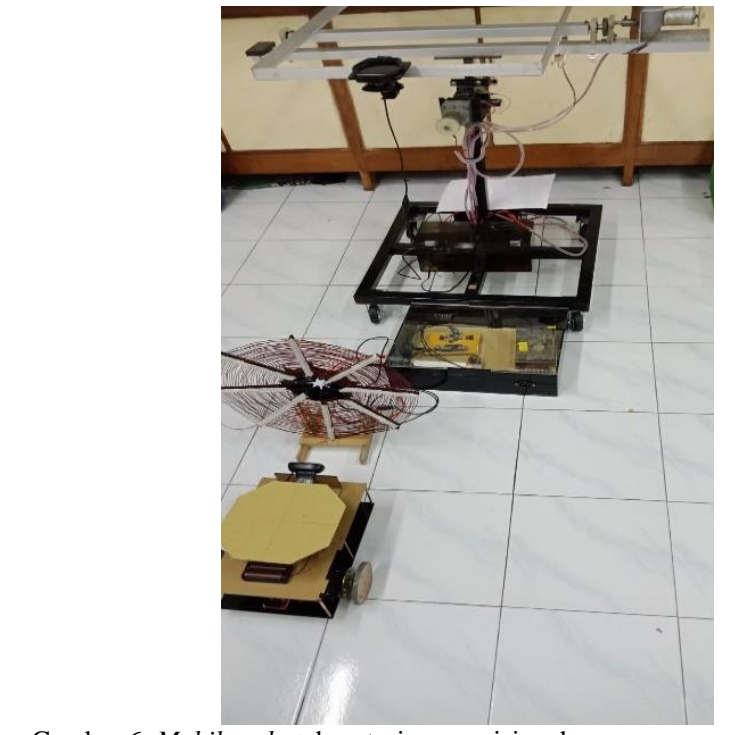

Gambar 6. Mobile robot dan stasiun pengisian daya.

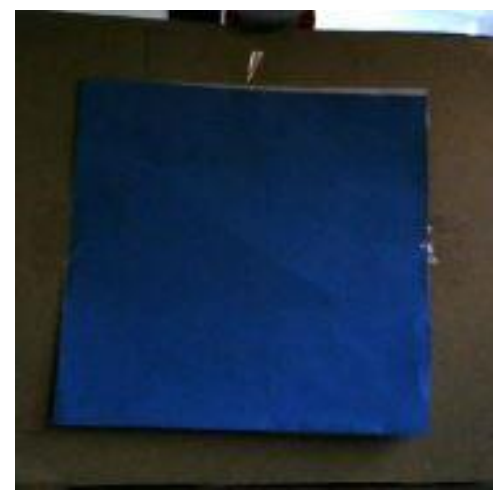

Gambar 7. Target yang dituju mobile robot.

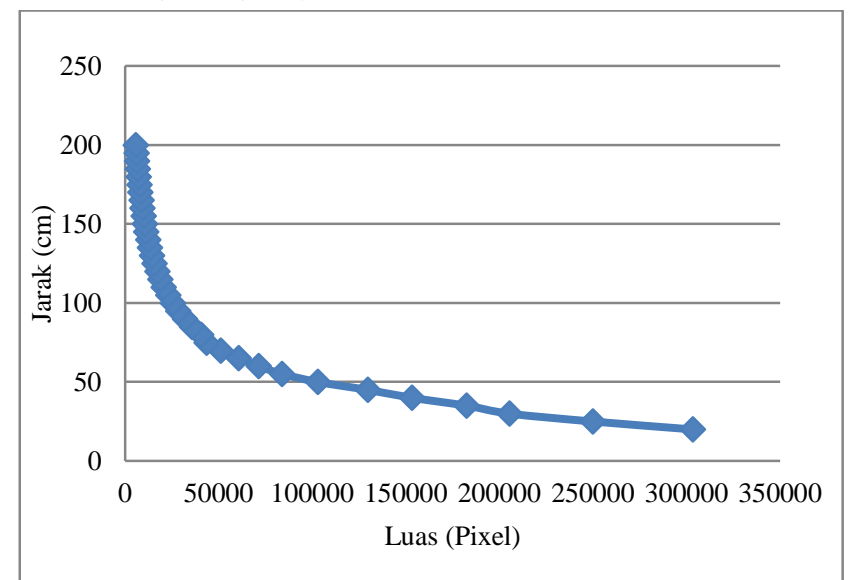

Gambar 8. Grafik perbandingan jarak dan luas.

Tabel 1.

Data perbandingan jarak asli dengan jarak hasil regresi.

\begin{tabular}{ccccc}
\hline \hline No. & Jarak Asli $(\mathrm{cm})$ & $\begin{array}{c}\text { Jarak Hasil } \\
\text { Regresi } \\
(\mathrm{cm})\end{array}$ & $\begin{array}{c}\text { Error } \\
(\mathrm{cm})\end{array}$ & $\begin{array}{c}\text { Tingkat } \\
\text { Keberhasilan } \\
(\%)\end{array}$ \\
\hline 1 & 20 & 27 & 7 & 65 \\
2 & 30 & 32 & 2 & 93,4 \\
3 & 40 & 40 & 0 & 100 \\
4 & 50 & 48 & 2 & 96 \\
5 & 60 & 59 & 1 & 98,3 \\
6 & 70 & 70 & 0 & 100 \\
7 & 80 & 81 & 1 & 98,75
\end{tabular}

8

9

$$
90
$$

100

110

120

130

140

150

160

170

180

190

200
92

103

\begin{tabular}{cc}
92 \\
103 \\
114 \\
122 \\
00 \\
133 \\
0 \\
139 \\
148 \\
0 & 161 \\
170 \\
183 \\
192 \\
\hline 0
\end{tabular}

$\begin{array}{cc}2 & 98,9 \\ 3 & 97 \\ 4 & 96,4 \\ 2 & 98,3 \\ 3 & 97,7 \\ 1 & 99,3 \\ 2 & 98,7 \\ 1 & 99,4 \\ 0 & 100 \\ 3 & 98,3 \\ 2 & 98,9 \\ 4 & 98\end{array}$

\section{B. Pengujian Jarak terhadap Target dengan Regresi}

Pada bagian ini dilakukan pengujian untuk mendapatkan jarak antara mobile robot dengan target dengan mengambil data luas target terhadap target dengan menggunakan jarak asli sebesar $20 \mathrm{~cm}$ hingga $200 \mathrm{~cm}$ dengan interval $5 \mathrm{~cm}$. Hasil pengujian ini ditunjukkan pada Gambar 8. Sedangkan hasil perhitungan dari regresi data perbandingan luas dan jarak ditunjukkan pada Tabel 1. Dari hasil pengujian jarak terhadap target menggunakan metode regresi memiliki nilai kesalahan paling tinggi saat pengujian pada jarak $20 \mathrm{~cm}$ yaitu sebesar $65 \%$. Untuk pengujian lainnya, nilai kesalahan yang didapatkan tidak ada yang besarnya melebihi $5 \%$. Tingkat keberhasilan rata - rata yang didapatkan yaitu sebesar $96,44 \%$.

\section{Pengujian Mobile Robot dengan Set Point Titik Tengah}

Pada bagian ini dilakukan pengujian motor dc mobile robot dengan kontrol proporsional. Set point yang digunakan dalam percobaan ini adalah titik tengah objek yang terdeteksi. Jarak asli yang digunakan saat robot berhenti tetap sama yaitu $20 \mathrm{~cm}$. Nilai titik tengah masing - masing sumbu (x, y) yang dijadikan set point adalah 319 dan 239 pixel. Hasil pengujian ditunjukkan pada Tabel 2. Hasil dari pengujian gerak mobile robot menggunakan titik tengah target sebagai set point menghasilkan tingkat keberhasilan rata - rata sebesar $77,5 \%$. Hasil ini memiliki tingkat keberhasilan yang lebih kecil dari pada menggunakan luas dari target, tetapi pada pengujian ini mobile robot tidak hanya dapat mengatur kecepatan motornya saja tetapi juga dapat menentukan arah saat bergerak menuju ke target sehingga pergerakan robot dapat dilakukan tidak hanya dalam kondisi jalur yang lurus.

Tabel 2.

Hasil pengujian mobile robot dengan set point titik tengah objek.

\begin{tabular}{ccccc}
\hline \hline No. & $\begin{array}{c}\text { Jarak Awal dari } \\
\text { Target }(\mathrm{cm})\end{array}$ & $\begin{array}{c}\text { Jarak Saat } \\
\text { Berhenti } \\
(\mathrm{cm})\end{array}$ & $\begin{array}{c}\text { Error } \\
(\mathrm{cm})\end{array}$ & $\begin{array}{c}\text { Tingkat } \\
\text { Keberhasilan } \\
(\%)\end{array}$ \\
\hline 1 & 60 & 17 & 3 & 85 \\
2 & 80 & 15 & 5 & 75 \\
3 & 100 & 13 & 7 & 65 \\
4 & 120 & 15,5 & 4,5 & 77,5 \\
5 & 140 & 14 & 6 & 70 \\
6 & 160 & 17 & 3 & 85 \\
7 & 180 & 16 & 4 & 80 \\
8 & 200 & 14 & 6 & 70 \\
9 & 220 & 18 & 2 & 90 \\
\hline \hline
\end{tabular}


Tabel 3.

Hasil pengujian akhir pada mobile robot.

\begin{tabular}{ccccc}
\hline \hline No. & $\begin{array}{c}\text { Jarak Awal dari } \\
\text { Target }(\mathrm{cm})\end{array}$ & $\begin{array}{c}\text { Jarak Saat } \\
\text { Berhenti } \\
(\mathrm{cm})\end{array}$ & $\begin{array}{c}\text { Error } \\
(\mathrm{cm})\end{array}$ & $\begin{array}{c}\text { Tingkat } \\
\text { Keberhasilan } \\
(\%)\end{array}$ \\
\hline 1 & 250 & 10,5 & 9,5 & 52,5 \\
2 & 300 & 14,5 & 5,5 & 72,5 \\
3 & 350 & 16 & 4 & 80 \\
4 & 400 & 16 & 4 & 80 \\
5 & 450 & 13,5 & 6,5 & 67,5 \\
6 & 500 & 20,5 & 0,5 & 97,5 \\
\hline \hline
\end{tabular}

D. Pengujian Akhir pada Mobile Robot

Pada bagian ini dilakukan pengujian yang bersifat final dengan menggunakan objek yang disimulasikan sebagai stasiun pengisian daya dengan penanda menggunakan warna biru sesuai dengan hasil percobaan sebelumnya, hanya saja memiliki ukuran yang lebih besar agar dapat dilihat oleh mobile robot dari jarak yang cukup jauh. Penanda digunakan untuk mengindikasikan bahwa objek adalah target yang akan dituju oleh mobile robot. Pengujian akhir ini dilakukan percobaan sebanyak enam kali, ditunjukkan pada Tabel 3. Pada pengujian ini, jarak yang digunakan sebagai acuan adalah $20 \mathrm{~cm}$. Kesalahan yang diperoleh bervariasi yang disebabkan oleh kondisi pencahayaan yang tidak tetap. Kesalahan paling kecil terdapat pada pengujian dengan jarak tejauh yaitu $500 \mathrm{~cm}$ dengan nilai kesalahan sebesar $0,5 \mathrm{~cm}$ dari hasil yang diharapkan. Secara keseluruhan, rerata tingkat keberhasilan pada pengujian ini adalah $75 \%$.

\section{KESIMPULAN}

Hasil yang didapat setelah melakukan beberapa percobaan menunjukkan bahwa besar luas dari target yang dideteksi kamera dipengaruhi oleh jarak antara kamera pada mobile robot dengan target. Percobaan yang dilakukan pada mobile robot untuk bergerak menuju target menggunakan titik tengah frame sebagai set point dan luas target sebagai acuan untuk mengatur kecepatan dan arah dari robot yang dikontrol menggunakan kontrol proporsional yang akan mengatur sinyal PWM dari motor dc pada robot. Titik tengah dan luas target didapat dengan menghitung moments pada contour dari target. Percobaan dengan metode ini memiliki tingkat keberhasilan sebesar $75 \%$.

\section{DAFTAR PUSTAKA}

[1] Watiasih R, Rivai M, Wibowo R A and Penangsang O 2017 Path Planning Mobile Robot Using Waypoint for Gas Level Mapping 2017 International Seminar on Intelligent Technology and Its Applications (ISITIA) (IEEE) pp 244-9

[2] Luo R C, Liao C T and Lin S C 2009 Multi-Sensor Fusion for Reduced Uncertainty in Autonomous Mobile Robot Docking and Recharging 2009 IEEE/RSJ International Conference on Intelligent Robots and Systems (IEEE) pp 2203-8

[3] Wang W, Li Z, Yu W and Zhang J 2009 An Autonomous Docking Method Based On Ultrasonic Sensors for Self-Reconfigurable Mobile Robot 2009 IEEE International Conference on Robotics and Biomimetics (ROBIO) (IEEE) pp 1744-9

[4] Suman S K and Giri V K 2016 Speed Control of DC Motor Using Optimization echniques based PID Controller 2016 IEEE International Conference on Engineering and Technology (ICETECH) (IEEE) pp 5817

[5] Rivai M, Suwito M, Chondro P and Ruan S-J 2015 Design and Implementation of A Submerged Capacitive Sensor in PID Controller to Regulate The Concentration of Non-denatured Ethyl Alcohol 2015 International Seminar on Intelligent Technology and Its Applications (ISITIA) (IEEE) pp 45-50

[6] Anon Logitech Support + Downloads

[7] Anon Christianto Tjahyadi

[8] Bradski G, Kaehler A, Cambridge B ·, Farnham ·, Köln ·, Sebastopol ·, Taipei · and Tokyo $\cdot 2008$ Learning OpenCV

[9] Lang H, Wang Y and Clarence W de S 2010 Vision Based Object Identification and Tracking for Mobile Robot Visual Servo Control IEEE ICCA 2010 (IEEE) pp 92-6

[10] Kurniawan A A, Rivai M and Budiman F 2016 Sistem Pemandu Pendaratan pada Balon Udara Berbasis Pengolahan Citra dan Kendali PID J. Tek. ITS 5 A179-84

[11] Krisrenanto D, Rivai M and Budiman F 2017 Identifikasi Jumlah dan Tingkat Aktivitas Orang Berbasis Pengolahan Citra Menggunakan Raspberry Pi J. Tek. ITS 6 105-9

[12] Ieee 20122012 International Conference on Advances in Engineering, Science and Management. (IEEE)

[13] Wijaya P D, Rivai M, Tasripan T and Tasripan T 2017 Rancang Bangun Mesin Pemotong Styrofoam 3 Axis Menggunakan Hot Cutting Pen dengan Kontrol PID J. Tek. ITS 6 A766-770 